scrofulous diathesis of the patient, the sore again broke out, attend. ed with exfoliation of the tibia to a large extent. Numerons pieces of bone were from time to time discharged. 'The patient was wasting, and the case, at best, seemed about to prove a lingering and trying one, with a useless limb at last, even if it should beal. It whs therefore proposed to remove the diseased and deformed limb, by amputation above the knee. 'The patient readily acquiesced, and the operation was performed on the $22 \mathrm{~d}$ of $\mathrm{July}, 1856$, by Dr. A. L. Hobarl, of Southborough, who was ably assisted by Dr. Carpenter of Upton, and by Drs. Enos and Geo. Hoyt of Framingham. A mixture of equal parts of ether and chloroform-about three ounces for the whole operation-was administered, and the patient behaved admirably under its influence. 'T'he flap operation was performed, an inch below the centre of the femur, and it was done, in every respect, as in the case I reported for your Journal of Nov. 8th, 1854. The cold-water dressing was applied to the stump. Upon examination of the leg after the amputation, the tibia was found to be exfoliated to the ihickness of a case-knife.

'The thigh was off in thirty-five seconds, and the ligatures were all placed in liventy minutes. The stump healed kindly. The last ligature came away on the eighteenth day. In the case of amptitation of the thigh by Dr. Hobart, at Marlborough, Aug. 17th, 185.1, the ligature of the fenoral artery came away on the 16th clay. But in the case of amputation of the fore-arm at Southborough, by the same operator, on the 3d of July last, the ligature of the radial artery could not be removed till the thirty-first day.

I have recently examined the stump at Milford. It is firm, and of good shape to receive a false limb. The health of the patient is good. Yours truly, J. W. Brown.

Framingham, Sept. 26th, 1856.

CASE OF HYSTERIA, SIMULATING HEART DISKASE.

BY PHLLP BURROWhs, ESQ., M.R.C.8., SURGEON TO THE LONDON CITY MISSION.

I was requested, some time ago, to see the daughter of a solicitor. Her father informed me that she was laboring under " heart disease." She was 17 years of age, with fair hair, blue eyes, and florid complexion. Her usual state of health had been good up to 1849 , when she had a severe illness, but I was unable to learn what its nature was, with the exception that she lay in a state of insensibility for two days, suffering more or lese from the symptoms until the period she came under my care. The catamenia appeared at 15 , but have never been regular as to timo or quantity, sometimes two months elapsing between the periods, the quantity being small, and color paler than natural.

When I first saw her, she complained of great pain over the entire cardiac region, greatly increased by pressure, so much so as almost to preclude the stethoscopic examination; decubitus more eacy 
on the leff side; pain and heart's action increased by turning round; dyspncea distressing; heart's impulse slow and labored, increased in extent so as to be heard above the clavicle on the right side; apex of the heart somewhat lower than natural; first sound dull and prolonged, with a slight blowing murmur over the second cartilage on the right side; second sound natural; rhythm of the pulse regular, and beat corresponding, with the heart's; there is no venous murmur ; heart's dulness augmented in area ; carotid pulsation visible; dull, aching pain over the forehead; no muscex volitantes or visual illusions of any kind ; tongue clean; bowels confined, which is usual with her.

She was ordered six leeches over the cardiac region, and the bleeding to be promoted by warm fomentations; the bowels were evacuated with infusion of senna and Rochelle salts; after which, she took the following draught three times daily:-Bicarbonate of potassium, ten grains; tincture of hyoscyamus, half a drachm; hydrocyanic acid (Sch.), two drops; cimnamon water one ounce. The diet to consist of boiled mutton and stale bread, with cocoa or milk for breakfast and tea, but no tea or coffee.

Under this treatment, the heart's action was quieted, the dyspnœa decreased, the pain was lessened, and after continuing it for ten days, five grains of the ammonio-tartrate of iron was added to the draught, and the potash omitted. I kept her on this plan for three weeks, at which time I discontinued my attendance. 'The heart's action was then moderate, the pain entirely gone, there was no dyspncea, and the murmur could only be heard at times. I roquested particular attention to diet, her bowels, and the gradual discontinuance of the medicine.

I had ceased my attendance on her for about ten days, when I was again requested to see her (April 15th, 1851), and found her in a most violent paroxysin, tearing her hair, beating the bed, and throwing everything from ber with the greatest possible force. Her molher told me she had been silent for two days, during which time her bowels were confined, when she suddenly, and withoul giving any warning, fell into the state in which I found her. The fuce was flushed, but there was no foaming at the mouth, and the spasmodic actions were irregular; occasionally there was a slight alternpt to laugh and talk, but she was totally unconscious of everything passing around her; the abdomen was highly tympanitic. I ordered her twenty drops of Battley's sedative solution, in camphor mixture, every two hours, as long as the paroxysm should last, and an enema of assafoctida and turpentine. On seeing her again in three hours, she was more calm and composed; sensibility was in a great measure relurned; when spoken to, she answers, and then laughs violently, and sits up, picking the clothes, and everything else that comes in her way; only a small quantity of urine passed from the bladder, high colored, without any trace of albumen wilh heat and nitric acid; tongue white, and pulse feeble. Ordered, tincture of assafœtida, a drachm and a half; rectified ether, a drachm and a 
half; Battley's solution, half a drachm; camphor mixture, three ounces and half; mix. One ounce every four hours.

April 16th.- She is more composed; bowels still confined, and she complains of great pain in the head. To continue the mixture without the opium, and have a stimulating aperient draught immediately.

171h.-'The bowels have acted twice, but there is still pain in the head, and slight indistinctness in her articulation, with occasional muttering, although quite sensible when her attention is roused. The catamenia have not appeared for six weeks. Ordered, assafœtida gum, one grain; sulphate of iron, two grains; decoction of powdered aloes, one grain: make two pills, to be taken every night. Also a draught, consisting of one drachm of tincture of valerian, half a drachın of spirit of foetid arnmonia, and one ounce of camphor mixture; to be taken three times a day.

18 th.-Was very restless up to three this morning, since which time she has enjoyed a quiet sleep. Her speech is now quite indistinct, and cannot be understood at all. She is perfectly sensible when roused, and puts her tongue out very well, without its being drawn to either side; neither sensation nor motion at all impaired. When asked if her head aches, she moves her hand all over it. To have eight leeches applied to the vulva, and mustard plasters to the nape of the neek, and the aperient draught if necessary. Continue pills and mixture.

19th.-The leeches have been applied, with the greatest relief to the head. She appears better in every respect; the articulation, however, is still most imperfect, she being only able to utter a word here and there. 'The bowels have been freely moved, and she has passed a large quantity of clear urine; the pulse continues feeble. Full diet; medicines continued.

22d.-C'The catamenia appeared yesterday morning. She is improving last; perfectly rational; no appearance of restlessness or childishness; speech much the same as at last report. I examined the heart carefully this morning; its action is regular, force natural; the murmur has disappeared; there is no dyspncea, or any symptom, either local or general, to indicate disease of the heart. She continues on the same trealment.

2th.-Her speech suddenly returned yesterday morning, and she continues to improve in every respect.

From this time she remained under my care for several weeks, during which period the same principle of treatment was kept up, and her health was completely established. I have lately seen her, and understand that she has continued in perfect healih ever since. The calarnenia return regularly, and she is never troubled with palpilation. She takes regular exercise, and sponges herself every morning with cold salt-and-water.

With regard to the general treatment of hysteria, I have found no class of remedies so useful as the fœtid gums, variously com. bined, either with sedatives or narcotics and steel; and for the re- 
lief of the local pains, aconite, chloroform, and belladonna. The liniment which I lave found the most useful is the following :Tincture of aconite, half an ounce; chloroform, three drachms; soap liniment and compound camphor liniment, of each one ounce and a half. This should be rubbed imto the seat of pain, and if necessary a piece of lint soaked in it, and applied under oiled silk.London Lancet, Sept. 6th, 1856.

\section{3ỉulfogianyteal Notices.}

Memoir of Moreton Stille, M.D. Read before the College of Physicians of Philadelphia, April 2d, 1856. By Samuel L. Hollingsworth, M D. Philudelphia. 1856 . pp. 35.

Tris short memoir has been upon our table for some weeks, and we cannot permit to pass unnoticed, our opinion of its truthfulness, and thorough appreciation of the character of one whose friendship we shall always consider it a privilege to have been permitted to enjoy. It wns our good fortune to pass some months of the winter of 1844-5 with $\mathrm{Dr}$. S. and a few other American students, in Dublin; and his untiring, conscientious devotion to his studies, was something quite remarkable, and the subject of general comment. 'The unbounded hospitality of the profession in Dublin is proverbial, and few there are at 23 , who can resist the charms of social life thus freely offered them; but for him, professional duties clatined his first love, and he denied himself every pleasure which could in any way interfere therewith. In the words of his biographer, "whatever he undertook, he applied himself to with a quiet determination, from which no obstacle or allurement ever diverted him for a moment."

As a natural result of such application, Dr. Stillé, though hardly 33 years of age at the time of his death, had already attained an enviuble po. sition in Philadelphia, among those competent to judge of his medical acquirements. Nor was his reputation confined solely to the city of his adoption; his writings, particularly the 'Trentise on Medical Jurisprudence, of which he was one of the editors, had brought him into favorable notice throughout the country, and every prospect was fair for a distinguished future, had his life been spared.

The memoir, it is gratifying to perceive, appears as a part of the Transactions of a scientific body. This is as it should be, for
"He that lacks time to mourn, lacks time to mend.
Eternity mourus that. 'T'is an ill cure
For life's worst ills, to have ub time to feel thom.
Where sorrow's held intrusive, and turned out,
There wisdom will not enter, nor true power,
Nor aught that dignifies humanity."

Practical Anatomy; a New Arrangement of the London Dissector. With Mlustrations. By D. Hayns AGNEW, M.D., Lecturer on Anatomy, and Surgeon to the Philadelphia Hospital. Philadelphia: J. B. Lippincott \& Co. 1856. 12mo. pp. 310.

Tuis work is a condensed guide for the use of the student engaged in the stindy of practical anatomy. Every thing not essential to his wants is omitted, the object of the author having been the economy of the student's 